\title{
Promoção da saúde por meio da música em uma penitenciária feminina: relato de experiência
}

\section{Health promotion through music in a female penitentiary: an experience report Promoción de la salud a través de la música en una penitenciaría femenina: relato de experiencia}

\author{
Jeane Barros de Souza iD \\ Universidade Federal da Fronteira Sul - Chapecó (SC) - Brasil \\ Odila Migliorini Rosa (iD \\ Universidade Federal da Fronteira Sul - Chapecó (SC) - Brasil
}

Simone dos Santos Pereira Barbosa (iD

Universidade Federal da Fronteira Sul - Chapecó (SC) - Brasil

Kelly Cristina de Prado Pilger iD

Universidade Federal da Fronteira Sul - Chapecó (SC) - Brasil

Tainá de Miranda Marquesini (iD

Universidade Federal da Fronteira Sul - Chapecó (SC) - Brasil

\author{
Emanuelly Luize Martins \\ Universidade Federal de Santa Catarina - Chapecó (SC) - Brasil
}

\section{RESUMO}

Objetivo: Compartilhar a experiência de promover saúde nas mulheres privadas de liberdade e das agentes penitenciárias, tendo a música como tecnologia de cuidado. Síntese dos dados: Trata-se de um relato de experiência de uma ação extensionista universitária do programa Musicagem, que ocorreu em uma penitenciária feminina de um município do Oeste Catarinense, Brasil, em dezembro de 2019, com o intuito de celebrar o Natal. Após a realização de planejamento e ensaio, o grupo concretizou a atividade, cantando para as detentas e funcionárias ao longo dos corredores da penitenciária. A música despertou abraços, choros e gratidão, tanto para as mulheres privadas de liberdade como para as agentes penitenciárias, que cantaram as músicas com a equipe extensionista, participando ativamente da atividade. Para os discentes e docentes, a experiência oportunizou reflexão sobre as condições de saúde no ambiente prisional, evidenciando a importância de outras ações semelhantes nesse local. Conclusão: A experiência mostrou a relevância da intersetorialidade. Repercutiu em benefícios para todos os envolvidos, demonstrando que a música é uma tecnologia leve, de baixo custo, que pode ser empregada para promover a saúde no espaço penitenciário, trazendo emoções e momentos de reflexão e lazer de maneira humanizada e integral.

Descritores: Promoção da Saúde; Prisioneiros; Música; Mulheres; Saúde da Mulher.

\section{ABSTRACT}

Objective: To share the experience of promoting the women deprived of liberty and penitentiary agents' health with music as a caring technology. Data synthesis: it is an experience report of a university extension action of the Musicagem program carried out in a female penitentiary in a municipality in the West of Santa Catarina, Brazil, in December 2019, to celebrate Christmas. After planning and rehearsing, the group carried out the action, singing to prisoners and employees along the penitentiary corridors. The music aroused hugs, cries, and gratitude for women deprived of their liberty and for the penitentiary agent, who sang the songs with the extension team, actively participating in the activity. For students and professors, the experience provided an opportunity to reflect on health conditions in the prison environment, highlighting the relevance of other similar actions in this place. Conclusion: Experience has shown the relevance of inter-sectorality. It has repercussions in benefits for all those involved, demonstrating that music is a light, low-cost technology that can be used to promote health in the prison space, bringing emotions and moments of reflection and leisure in a humanized and integral way.

Descriptors: Health Promotion; Prisoners; Music; Women; Women's Health. 


\section{RESUMEN}

Objetivo: Compartir la experiencia de promocionar salud para mujeres privadas de libertad y de las agentes penitenciarias a través de la música como la tecnología del cuidado. Síntesis de los datos: Se trata de un relato de experiencia de una acción extensionista universitaria del programa "Musicagem" que se dio en una penitenciaria femenina de un municipio del Oeste del estado de Santa Catarina, Brasil, en diciembre de 2019 con el objetivo de celebrar na Navidad. Después del planeamiento y el ensayo, el grupo ha concretizado la actividad cantando para las detentas y las funcionarias a lo largo de los pasillos de la penitenciaria. La música ha despertado los abrazos, los llantos y la gratitud para las mujeres privadas de libertad y las agentes penitenciarias que cantaron las músicas con el equipo extensionista participando activamente de la actividad. Para los discentes y los docentes, la experiencia ha permitido una reflexión sobre las condiciones de salud del ambiente de la prisión evidenciando la importancia de otras acciones semejantes en ese local. Conclusión: La experiencia ha presentado la relevancia de la intersectorialidad. También ha repercutido los beneficios para todos los involucrados demostrando que la música es una tecnología leve y de bajo coste que puede ser usada para la promoción de la salud en el espacio penitenciario conduciendo las emociones y los momentos de reflexión y de ocio de manera integral y humanizada.

Descriptores: Promoción de la Salud; Prisioneros; Música; Mujeres; Salud de la Mujer.

\section{INTRODUÇÃO}

Por longos anos, a saúde foi considerada ausência de doença. No entanto, ampliou-se o olhar sobre o conceito de saúde, sendo compreendida como o bem-estar físico, mental e social. Para atingir esse estado de completo bem-estar, indivíduos e grupos devem saber identificar aspirações, satisfazer necessidades e modificar favoravelmente o meio ambiente. No Brasil, a saúde é garantida pelo Estado, por meio de estratégias de prevenção, promoção e recuperação, o que contribui para a qualidade de vida da população(1). Mas, decorridos 30 anos da criação do Sistema Único de Saúde (SUS), ainda se faz necessário superar o modelo centrado na doença para transformar expressivamente o modo de produzir saúde e enfrentar os determinantes sociais do processo saúde-doença ${ }^{(2)}$, ou seja, as condições sociais em que as pessoas vivem e trabalham.

A promoção da saúde envolve estratégias de produzir saúde, que busca atender às necessidades e qualificar a vida de indivíduos e coletividades. A Política Nacional de Promoção da Saúde (PNPS), criada em 2006 e revisada em 2014, reconhece a importância dos condicionantes e determinantes sociais da saúde no processo saúde-doença e considera a intersetorialidade e a criação de redes de corresponsabilidade para a melhoria da qualidade de vida da população. Nesse âmbito, fica evidente a transversalidade da promoção da saúde, que deve ocorrer em todos os cenários da rede de atenção à saúde e sociedade, podendo utilizar diversas estratégias de atuação(2,3).

Entre as ações realizadas para promover a saúde encontra-se a música, que é considerada uma tecnologia leve e está presente na vida do ser humano desde seu início, sendo uma combinação de sons, letras e ritmos harmônicos que permitem aos sujeitos expressarem seu sentimentos e emoções, reduzindo as sensações de estresse, tristeza e raiva, aumentando os sentimentos de alegria, paz e relaxamento. Diante dos seus benefícios, a prática musical vem sendo empregada constantemente na área da saúde, propiciando resultados positivos na saúde mental dos indivíduos ${ }^{(4,5)}$.

No âmbito da formação em enfermagem, as ações extensionistas possibilitam promover a saúde de indivíduos e coletividades, bem como aproximar os docentes e discentes à realidade social, evidenciando na vivência prática os determinantes de adoecimento para, a partir de então, desenvolver atividades em prol do bem-estar de uma população( ${ }^{(6)}$. Nesse contexto, são diversas as possibilidades e tecnologias para promover a saúde da comunidade, sendo uma delas o emprego da música.

No ano de 2018, ao considerar a música como uma relevante tecnologia de cuidado para promover saúde, docentes e discentes de um curso de graduação em enfermagem de uma universidade pública do Sul do Brasil organizaram um programa de extensão. A partir de então, semanalmente passaram a desenvolver intervenção musical em dois hospitais públicos de um município catarinense, cantando músicas reflexivas, com acompanhamento de violão, violino e percussão, para indivíduos hospitalizados, seus familiares e profissionais da saúde. No entanto a equipe de atuação do programa de extensão começou a receber convites para realizar apresentação musical em outros cenários da sociedade, para além do espaço hospitalar, como na penitenciária feminina.

Em uma pesquisa, a música foi citada como um entre cinco elementos que colaboraram para conviver melhor com as mudanças diante do cotidiano do aprisionamento de mulheres, sendo eles: fé, trabalho, música, companheiras de cárcere, filhos e a espera pela liberdade. $O$ desenvolvimento de tais mecanismos de resiliência são relevantes na busca de superar sofrimentos de mulheres no cárcere ${ }^{(7)}$. 
O sistema prisional possui superlotação e condições precárias de sobrevivência, faltando recursos humanos, físicos e materiais para condições de vida saudáveis. Além disso, o encarceramento feminino carece de implementação de políticas sociais, pois, apesar de haver leis públicas, ainda há falhas no acesso à serviços de saúde, o que pode tornar esse público vulnerável e desassistido de cuidados e ações de prevenção e promoção( ${ }^{(8)}$. Para tanto, torna-se necessário que os profissionais, tanto da unidade prisional quanto dos serviços de saúde, encontrem estratégias intersetoriais para promover a saúde das mulheres privadas de liberdade.

Diante dos resultados exitosos da ação extensionista em uma unidade prisional, emergiu este artigo, com o objetivo de compartilhar a experiência de promover saúde nas mulheres privadas de liberdade e das agentes penitenciárias, tendo a música como tecnologia de cuidado.

\section{SÍNTESE DOS DADOS}

Trata-se de um relato de experiência de uma ação extensionista universitária que se fundamentou nos referenciais teóricos da promoção da saúde e dos benefícios da música para promover saúde em uma unidade prisional. $O$ conceito de promoção da saúde apresentou-se como essencial nos sistemas de saúde, na Declaração de Alma-Ata, em 1978. Mas na Carta de Ottawa, em 1986, emergiu uma reflexão aprofundada sobre a promoção da saúde, no mesmo ano em que ocorria a VIII Conferência Nacional de Saúde no Brasil( ${ }^{(9)}$.

A promoção da saúde é considerada uma estratégia de enfrentamento dos problemas de saúde que ocorrem na população. É o processo de capacitar o indivíduo a melhorar sua qualidade de vida e seu bem-estar físico, psíquico, social e espiritual, além de fornecer condições saudáveis, como o ambiente em que o envolve, considerando os determinantes sociais da saúde. Assim, busca-se empoderar os indivíduos, agindo de maneira intersetorial e transversal, com vistas a diminuir as iniquidades ${ }^{(10)}$.

A música é um instrumento que auxilia na promoção da saúde, interfere direta e indiretamente no bem-estar dos indivíduos, permitindo que os níveis de ansiedade e de estresse sejam aliviados, e a tristeza pode se transformar em alegria e tranquilidade. Ainda, possibilita momentos de lazer e distração, em especial aos indivíduos detentos, sendo uma maneira de sair da realidade que vivem. Somado a isso, a música oportuniza vagar por lembranças e bons momentos guardados na memória ${ }^{(11)}$, visto que as detentas estão distantes dos seus familiares, tendo, de forma indireta, que criar vínculo com as demais mulheres da penitenciária, pois será com elas que passarão inúmeros dias, em um local onde nenhuma queria estar. Nesse cenário, é premente encontrar força, motivação e esperança para seguir o dia a $\operatorname{dia}^{(7,11)}$.

A experiência foi realizada pelo programa de extensão denominado Musicagem, que evidencia em seu nome a união da enfermagem e da música em prol da promoção da saúde dos indivíduos, que é o maior objetivo da sua existência. Tal programa é composto por oito participantes, sendo cinco vocalistas e três instrumentistas, entre duas docentes e seis discentes de um curso de graduação em enfermagem de uma universidade federal no Sul do Brasil.

Para ingressar no programa de extensão, os acadêmicos se voluntariam e aguardam a seleção anual, conforme a habilidade musical de cada um. A equipe do programa atua semanalmente em dois hospitais públicos, mantendo ensaios periódicos para a preparação de músicas para integrar o repertório musical, que é composto por canções com letras reflexivas que abordam temáticas sobre amor, paz, fé, esperança, alegria e vida.

A experiência aqui relatada ocorreu em uma penitenciária feminina de um município de Santa Catarina, Brasil, em dezembro de 2019, em que se percorreram as dependências dos corredores das celas e do pátio onde as mulheres privadas de liberdade tomavam sol.

Durante o percurso na unidade prisional, a agente penitenciária que acompanhou a equipe do programa de extensão informou que a penitenciária foi inaugurada no ano de 2018, com 286 vagas. Possui áreas específicas para gestantes, materno-infantil, assim como a separação das galerias da instituição, que são organizadas por regime de pena, sendo eles: provisório, fechado e semiaberto. Foi constatado que as práticas de enfermagem são ativas dentro da unidade prisional, em todos esses setores, em busca de prestar um cuidado humanizado e de qualidade.

Para o desenvolvimento da ação, primeiramente a direção da penitenciária feminina entrou em contato com a equipe do programa de extensão, solicitando uma atividade musical no local, a fim de organizar uma atividade especial em comemoração ao Natal. As docentes e discentes aceitaram imediatamente o convite e apreciaram a oportunidade de promover saúde no ambiente prisional por meio da música, pois tratava-se de um espaço de difícil acessibilidade para a realização de ações extensionistas.

Para tanto, os integrantes do Musicagem reuniram-se para ensaiar e elaborar uma estratégia para desenvolver a atividade musical, buscando dialogar com a direção da unidade prisional para compreender a planta física do local 
e as demais orientações, para evitar possíveis imprevistos. A partir disso, pensando em promover um momento reflexivo, acolhedor e seguro, o grupo seguiu todas as recomendações e selecionou músicas com letras pertinentes ao momento, melodias calmas, bem como canções natalinas que abordavam sobre o amor e o verdadeiro sentido do Natal, a fim de oportunizar uma experiência prazerosa e, ao mesmo tempo, que despertasse curiosidade, visto que as detentas não tinham ciência da atividade preparada para elas.

Então, no dia agendado, uma manhã de dezembro de 2019, a equipe foi até a penitenciária feminina. Ao adentrar o local, o ambiente era gélido, escuro e silencioso. Os integrantes do Musicagem foram recebidos por uma agente penitenciária, que os conduziu durante toda a atividade, que durou aproximadamente três horas. Com a autorização da agente penitenciária, a equipe começou a cantar nos corredores de maneira improvisada, enquanto se dirigia até o local de cada apresentação musical. Esse feito encheu os corredores silenciosos com o som musical, que foi se multiplicando por todo o prédio, despertando profundamente a atenção das detentas, bem como da equipe profissional, que passou a seguir as docentes e discentes pelos corredores da unidade prisional, demonstrando apoio à ação de extensão.

Inicialmente, a equipe cantou para diferentes grupos de mulheres que estavam tomando banho de sol, promovendo troca de abraços e emoções entre elas, sendo observado pela equipe a expressão de sorrisos e lágrimas nas detentas. Durante as músicas, as mulheres começaram a cantar junto com os integrantes do Musicagem e realizaram vários abraços coletivos, agradecendo por meio de frases de gratidão e salva de palmas ao término de cada canção entoada.

Em seguida, a equipe dirigiu-se para o outro lado da penitenciária, cantando no trajeto até chegar nos corredores das celas. Nesse local, as detentas ficavam organizadas em celas menores, contendo apenas uma pequena janela que dava acesso ao corredor. Assim, os integrantes do Musicagem cantaram diferentes músicas no corredor, enquanto as detentas, pela janela das suas respectivas celas, observavam com olhares atentos. Algumas sorriam, outras choravam, demonstrando gratidão por meio de palavras expressas pelo momento que estavam vivendo. Ainda realizou-se uma atividade musical para as mulheres grávidas e para as que estavam amamentando seus filhos, na ala específica para esse público, que também choraram intensamente, demonstrando gratidão pelos momentos musicais partilhados no local. Enquanto isso, atrás da equipe do programa de extensão, aglomerou-se um grupo de agentes penitenciárias, que também choravam, aplaudiam, cantavam as músicas, agradecendo a oportunidade.

Nesse momento, a equipe do programa Musicagem sugeriu para que a direção da penitenciária reunisse, mesmo que brevemente, agentes penitenciários que atuavam na unidade, em um local, para que pudessem cantar especificamente para elas. A sugestão foi aceita e os integrantes do Musicagem começaram a cantar pelos corredores, convidando as funcionárias, que podiam se ausentar de seus postos para rapidamente se reunirem com eles. Já na sala, os integrantes do Musicagem foram cantando e dando as mãos para as profissionais, convidando-as para uma grande roda musical. A docente coordenadora do programa de extensão apontou brevemente sobre a importância do trabalho delas para a sociedade, instigando-as a promover o seu autocuidado para poder cuidar das pessoas ao seu redor e, assim, desenvolver com qualidade o seu trabalho, fortalecendo-se e empoderando-se. As mulheres mantiveram-se atentas a todas as palavras proferidas, se emocionaram e agradeceram intensamente pelo momento partilhado.

Para finalizar, foi entoada uma música natalina, integrando todas as agentes penitenciárias, que se abraçaram e cantaram com a equipe do programa de extensão. Os integrantes do Musicagem se despediram das funcionárias e foram cantando pelos corredores até a porta de saída, já com o convite para retorno na Páscoa de 2020. Mas, diante da situação de pandemia, imposta pela pandemia do novo coronavírus, ainda não foi possível retornar ao local.

O programa de extensão Musicagem integra ações de um estudo matricial que foi aprovado pelo Comitê de Ética em Pesquisa, com Parecer n. ${ }^{\circ}$ 3.305.186, com vistas a buscar evidências científicas sobre o uso da música como tecnologia de cuidado para promover saúde. Para ingressar na penitenciária feminina, a equipe de atuação respeitou todas as normas da instituição, utilizando vestimentas adequadas, conforme as recomendações da direção.

\section{A prática à luz de teoria...}

A experiência realizada na penitenciária feminina repercutiu em benefícios para as mulheres privadas de liberdade, bem como para as profissionais da instituição e para os integrantes do programa de extensão, promovendo a saúde de todos os envolvidos.

A concepção de promoção da saúde resultou da Carta de Ottawa, de $1986^{(12)}$, um processo transformador em busca de melhores condições de vida dos indivíduos e coletividades, que carece de profissionais críticos e capazes de adaptação aos inúmeros cenários, considerando a saúde como um conceito positivo. Conforme a PNPS, o cuidado em saúde deve ser integral, com ações promotoras que contribuam para a assistência à saúde, por meio de ferramentas inovadoras que sejam inclusivas e contributivas ${ }^{(2)}$, como o uso da música, resultando na qualidade de vida da população. 
A promoção da saúde não é responsabilidade exclusiva do setor saúde e vai para além de um estilo de vida saudável, seguindo na direção de um bem-estar global, ultrapassando o âmbito da Atenção Primária à Saúde (APS) para efetivar a qualidade de vida dos indivíduos e das coletividades, com apoio de outras políticas públicas que realizam a inclusão e diminuição das desigualdades em saúde, de maneira intersetorial ${ }^{(13)}$.

A unidade prisional possui uma realidade distinta de qualquer outro setor, mantendo-se como um espaço que isola os indivíduos privados de liberdade, tanto da sociedade quanto de algumas ações de saúde ${ }^{(9)}$. Sabe-se que o ambiente prisional não é um espaço acolhedor, possuindo estruturas físicas que estão aquém do ideal, com higiene e cuidados sanitários precários para condições de vida qualificadas ${ }^{(14)}$. Nesse sentido, revela-se a carência de ações promotoras de saúde, sendo relevante o despertar dos enfermeiros e demais profissionais da área para atuação nesse local.

A saúde das mulheres privadas de liberdade está garantida na Constituição Federal de 1988, que afirma que a saúde é um direito de todos e dever do Estado. Porém somente em 2003 esse público passou a ser reconhecido de forma específica, com a institucionalização do Plano Nacional de Saúde no Sistema Penitenciário (PNSSP), que visa promover a atenção integral à saúde, controlando doenças e agravos. Em 2014, surgiu a Política Nacional de Atenção Integral à Saúde das Pessoas Privadas de Liberdade no Sistema Prisional (PNAISP), com objetivos voltados para: o respeito aos direitos humanos e a justiça social; a integralidade da atenção à saúde; e a equidade frente às diferenças e singularidades desses indivíduos ${ }^{(9)}$.

De acordo com a PNSSP e a PNAISP, as equipes de saúde que atuam no sistema penitenciário integram a Atenção Básica $(A B)$ e possuem a competência de realizar a promoção, a prevenção e a recuperação em saúde, garantidos pelo Sistema Único de Saúde (SUS). Dessa forma, como em qualquer setor da AB, também é importante promover a saúde na unidade prisional, contribuindo para a qualidade de vida e o bem-estar das detentas e das agentes penitenciárias, facilitando as relações do cotidiano $^{(9)}$.

Uma pesquisa revelou que a música promove saúde ao proporcionar momentos de alegria, paz, esperança e distração(15). A música vem sendo utilizada como instrumento de promoção da saúde em diversos setores, por permitir a expressão de sentimentos e emoções, o que reduz a tensão, a ansiedade e o estresse ${ }^{(5,16)}$, corroborando os achados desta experiência, na qual, a partir da atividade musical, observou-se que as mulheres detentas expressaram seus sentimentos, apresentando momentos de choro, alegria e agradecimento. Além da expressão das emoções, acredita-se que as letras musicais permitiram que as mulheres vagassem entre suas lembranças e vivências fora do presídio, pois a música possibilita aos indivíduos a conexão com suas histórias de vida, encontrando e revivendo lembranças na memória que, até então, estavam esquecidas ${ }^{(17,18)}$.

A equipe do Musicagem adentrou na penitenciária feminina com o propósito principal de promover a saúde das mulheres detentas. No entanto, durante a experiência, promoveu a oportunidade para as agentes penitenciárias, que também careciam desse cuidado. Nesse sentido, a experiência também foi um momento de reflexão para as agentes penitenciárias, que se renovaram e se fortaleceram para dar continuidade ao serviço prestado, pois se sabe que o trabalho desenvolvido dentro das unidades prisionais é de alto risco, envolvendo inúmeros medos e receios, e extrema importância para manter a segurança da sociedade e dos detentos ${ }^{(19)}$.

As mulheres que trabalham como agentes penitenciárias carregam inúmeros estigmas no que tange às suas atribuições e à imagem dentro da unidade prisional, sendo ligadas à aparência masculina, forte e violenta. Além do estigma, também sofrem devido ao desgaste físico e mental com o grande número de detentas; com a insalubridade do espaço prisional, não havendo locais adequados para descanso e repouso; o pouco tempo para satisfazer as necessidades básicas, como ir ao banheiro; entre diversos outros fatores que podem desencadear estresse, insônia, nervosismo e depressão(20).

Ao implementar a música na unidade prisional, metaforicamente, foi como iluminar aquele ambiente, em que todos os indivíduos que estavam dentro daquele espaço foram modificando suas atitudes, transformando seus semblantes e abraçando-se, sendo beneficiados e envolvidos pela sensação de acolhimento e esperança. Por meio da música foi possível sorrir, relembrar, chorar, esperançar por um futuro diferente e renovar seus sentimentos para a época natalina, sensações destacadas pela utilização da música. Portanto, aponta-se a relevância de escolher as músicas apropriadas para cada situação, pois se trata de uma prática alternativa de saúde, que promove sensações únicas em cada indivíduo quando bem utilizada(16,21).

Somada às repercussões que a ação musical proporcionou para as mulheres privadas de liberdade e para as agentes penitenciárias, a experiência também afetou os discentes que a aplicaram, pois tiveram a oportunidade de ter contato com uma nova realidade. $O$ aprendizado e a experiência levaram as alunas a crer que essa tecnologia leve de cuidado da assistência de enfermagem pode ser utilizada em vários setores da sociedade, como na unidade prisional, ficando evidente, de maneira prática, que todo cidadão brasileiro tem o direito à saúde, incluindo a população 
encarcerada. Para além disso, ao adentrar a unidade prisional, pode-se refletir com criticidade acerca da assistência à saúde nesse local, que até então não tinha visibilidade na formação acadêmica e na vida das acadêmicas.

Dessa maneira, a experiência sensibilizou as docentes envolvidas no programa de extensão também, que se surpreenderam com os resultados exitosos da ação musical na penitenciária, despertando-se para a necessidade de dar continuidade e desenvolver outras atividades nesse espaço e em tantos outros que carecem de ações promotoras de saúde. Para as docentes ficou evidente que é tempo de ampliar as discussões sobre a saúde no sistema penitenciário, buscando aprimorar o desenvolvimento de habilidades e competências na formação de enfermeiros, com vistas a garantir os princípios do SUS a todos os brasileiros.

Como limitações da experiência cita-se a própria estrutura da penitenciária, pois, por ser um ambiente que envolve diversos processos burocráticos, dificulta a realização de ações extensionistas de maneira contínua no local. Além disso, houve dificuldades em conciliar horário entre os membros da equipe do programa de extensão com a disponibilidade da unidade prisional, que possibilitou a realização da atividade apenas no período matutino e/ou vespertino, com exclusão dos fins de semana, sendo exatamente o momento que os docentes e discentes estavam nas aulas universitárias. Portanto, foi necessário aguardar o término das aulas para que os integrantes do programa de extensão pudessem realizar a atividade musical.

\section{CONCLUSÃO}

A experiência demonstrou que a música é um relevante instrumento para promover saúde na unidade prisional de maneira integral e humanizada. Emergiram benefícios não apenas para as mulheres privadas de liberdade, mas também para as agentes penitenciárias, viabilizando momentos de reflexão, expressão de sentimentos e de despertar do ânimo para prosseguir na jornada da vida. Portanto, a música pode ser empregada na prática profissional de enfermagem, sendo uma tecnologia de cuidado de baixo custo, capaz de promover a saúde de indivíduos e coletividades, em diversos cenários de atuação, inclusive no sistema penitenciário.

\section{CONFLITOS DE INTERESSE}

Os autores declaram a inexistência de conflitos de interesses, tanto na execução da ação extensionista como na escrita deste manuscrito.

\section{CONTRIBUIÇÕES}

Jeane Barros de Souza, Odila Migliorini Rosa, Simone dos Santos Pereira Barbosa, Kelly Cristina de Prado Pilger, Tainá de Miranda Marquesini e Emanuelly Luize Martins contribuíram com a elaboração e delineamento do estudo; a aquisição, análise e interpretação dos dados; e a redação e/ou revisão do manuscrito. Todos os autores aprovaram a versão final enviada para publicação e são responsáveis por todos os aspectos do trabalho.

\section{REFERENNCIAS}

1. Senado Federal (BR). Constituição da República Federativa do Brasil: texto constitucional promulgado em 5 de outubro de 1988, com as alterações determinadas pelas Emendas Constitucionais de Revisão nos 1 a 6/94, pelas Emendas Constitucionais nos $1 / 92$ a 91/2016 e pelo Decreto Legislativo no 186/2008 [Internet]. Brasília: Senado Federal; 2016 [acesso em 2018 Set 3]. Disponível em: https://www2.senado.leg.br/bdsf/ bitstream/ handle/id/518231/CF88_Livro_EC91_2016.pdf

2. Malta DC, Reis, AAC, Jaime PC, Morais OL Neto, Silva MMA, Akerman M. O SUS e a Política Nacional de Promoção da Saúde: perspectiva resultados, avanços e desafios em tempos de crise. Ciênc Saúde Colet [Internet]. 2018 [acesso em 2020 Out 30];23(6):1799-809. Disponível em: https://www.scielo.br/pdf/csc/ v23n6/1413-8123-csc-23-06-1799.pdf

3. Ministério da Saúde (BR). Política Nacional de Promoção da Saúde: PNPS: Anexo I da Portaria de Consolidação $n^{\circ} 2$, de 28 de setembro de 2017, que consolida as normas sobre as políticas nacionais de saúde do SUS [Internet]. Brasília: Ministério da Saúde; 2018 [acesso em 2020 Out 31]. Disponível em: http:// bvsms.saude.gov.br/bvs/publicacoes/politica_nacional_promocao_saude.pdf

4. Cardoso AVM, Souza AAM, Silva PLN, Carvalho HLA, Alves ED, Aguiar WA Filho. Cuidando com arte 
a promoção da saúde por meio da música. Dialnet [Internet]. 2016 [acesso em 2020 Set 01];4(1):1-22. Disponível em: http://periodicos.unincor.br/index.php/revistaunincor/article/view/2531/pdf_472

5. Souza B, Barbosa SSP, Martins EL, Zanettini A, Urio A, Xirello T. A música como prática de promoção J na adolescência. Rev Enferm UFSM [Internet]. 2019 [acesso em 2020 Out 29];9(11): 1-15. Disponível em: https://periodicos.ufsm.br/reufsm/article/view/30379/html

6. Ferreira PB, Suriano MLF, Domenico EBL. Contribuição da extensão universitária na formação de graduandos de enfermagem. Rev Bras Enferm [Internet]. 2020 [acesso em 2020 Jun 15];73(6):e20180909. Disponível em: https://www.scielo.br/pdf/reben/v73n6/pt_0034-7167-reben-73-06-e20180909.pdf

7. Lima GMB, Pereira AF Neto, Amarante PDC, Dias MD, Ferreira MO Filha. Mulheres no cárcere: significados e práticas cotidianas de enfrentamento com ênfase na resiliência. Saúde Debate [Internet]. 2013 [acesso em 2020 Nov 05];37(98):446-56. Disponível em: https://www.scielo.br/pdf/sdeb/v37n98/a08v37n98.pdf

8. Nascimento LG, Bandeira MMB. Saúde Penitenciária, Promoção de Saúde e Redução de Danos do Encarceramento: desafios para a Prática do Psicólogo no Sistema Prisional. Psicol Cienc Prof [Internet]. 2018 [acesso em 2020 Ago 12];38(2):102-116. Disponível em: http://www.scielo.br/scielo.php?script=sci_ arttext\&pid=S1414-98932018000600102\&lng=en\&nrm=iso

9. Tavares MFL, Rocha RM, Bittar CM, Petersen CB, Andrade M. A promoção da saúde no ensino profissional: desafios na Saúde e a necessidade de alcançar outros setores. Ciênc Saúde Colet [Internet]. 2016 [acesso em 2020 Abr 03];21(1):1799-808. Disponível em: https://www.scielosp.org/article/csc/2016.v21n6/1799-1808/

10. Figueiredo DS, Heidemann ITSB, Fernandes GCM, Arawaka AM, Oliveira LS, Magagnin AB. Promoção da saúde articulada aos determinantes sociais: possibilidade para a equidade. Rev Enferm UFPE [Internet]. 2019 [acesso em 2020 Out 30];13(4):943-51. Disponível em: https://periodicos.ufpe.br/revistas/ revistaenfermagem/article/view/239123/31771

11. Rodrigues DF. A música como instrumento de humanização na saúde da mulher. Rev Eletrônica Acervo [Internet]. 2019 [acesso em 2020 Set 1];11(13):e1250. Disponível em: http://repositorio.ufu.br/ handle/123456789/27684

12. Carta de Ottawa: primeira Conferência Internacional sobre Promoção da Saúde [Internet]. 1986 [acesso em 03 Ago 2020]. Disponível em: http://bvsms.saude.gov.br/bvs/publicacoes/carta_ottawa.pdf

13. Pontes RP Filho, Andrade JBL. Corporeidade no sistema prisional. Somanlu Rev Estud Amazôn [Internet]. 2018 [acesso em 2020 Jun 10];17(1):144-56. Disponível em: https://periodicos.ufam.edu.br/index.php/ somanlu/article/view/4278

14. Silva GH, Piovesan JC. Música no ambiente hospitalar: uma probabilidade de proporcionar alegria e ludicidade na internação. Rev Eletrônica URI [Internet]. 2018 [acesso em 2020 Jun 10];14(26):204-19. Disponível em: http://www2.reitoria.uri.br/ vivencias/Numero_026/artigos/pdf/Artigo_17.pdf

15. Zanettini A, Souza JB, Franceschi VE, Finger D, Gomes A, Santos MS. Quem canta seus males espanta: um relato de experiência sobre o uso da música como ferramenta de atuação na promoção da saúde da criança. Rev Min Enferm [Internet]. 2015 [acesso em 2020 Mar 27];19(4):1060-4. Disponível em: https://cdn.publisher. gn1.link/reme.org.br/pdf/en_v19n4a19.pdf

16. Souza JB, Campagnoni JP, Barbosa SSP, Sauer AG, Zenenvicz LT, Brum CN, et al. Música no hospital: promoção da saúde na oncologia. Rev Bras Promoç Saúde [Internet]. 2019 [acesso em 2020 Set 1];32(1):18. Disponível em: https://periodicos.unifor.br/RBPS/article/view/8920/pdf

17. Motin FG, Silva LLF. Práticas de ensino de música no contexto prisional: análise comparativa de estudos de caso. Eur Rev Artistic Stud [Internet]. 2019 [acesso em 2020 Set 1];9(1):56-74. Disponível em: https://dialnet. unirioja.es/servlet/articulo?codigo $=7211925$

18. Guimarães AGC, Nero RM, Portela LC, Taets GGCC, Santo FHE, Bergold LB. Encontro musical como estratégia de cuidado para a promoção da humanização em uma instituição de longa permanência para idosos. Braz J Hea Ver [Internet]. 2020 [acesso em 2020 Out 31];3(5):13898-916. Disponível em: https://www. brazilianjournals.com/index.php/BJHR/article/view/17754/14396

19. Rudnick D, Schafer G, Silva JC. As máculas da prisão: estigma e discriminação das agentes penitenciária. 
Rev Direito GV [Internet]. 2017 [acesso em 2020 Ago 04];13(2):608-27. Disponível em: https://www.scielo.br/ scielo.php?pid=S1808-24322017000200608\&script=sci_arttext\&tIng=pt

20. Claro LBL, Delvo VN, Valente LR. Percepções de pacientes e profissionais da saúde sobre as visitas musicais do programa de extensão "boa noite, bom dia huap". Rev Conexão UEPG [Internet]. 2017 [acesso em 2020 Set 1];13(1):66-83. Disponível em: https://revistas2.uepg.br/index.php/conexao/article/ view/9278/5495

21. Silva LAGP, Baran FDP, Mercês NNA. A música no cuidado às crianças e adolescentes com câncer: revisão integrativa. Texto \& Contexto Enferm [Internet]. 2016 [acesso em 2020 Set 1];25(4):1-10. Disponível em: https://www.scielo.br/pdf/tce/v25n4/pt_0104-0707-tce-25-04-1720015.pdf

\section{Endereço do primeiro autor:}

Jeane Barros de Souza

Universidade Federal da Fronteira Sul

Rodovia SC 484/ Km 02, Fronteira Sul

CEP: 89815-899 - Chapecó SC - Brasil

E-mail: jeanebarros18@gmail.com

\section{Endereço para correspondência:}

Tainá de Miranda Marquesini

Universidade Federal da Fronteira Sul

Rodovia SC 484/ Km 02, Fronteira Sul

CEP: 89815-899 - Chapecó SC - Brasil

E-mail: taina.m.marquesini@gmail.com

Como citar: Souza JB, Rosa OM, Barbosa SSP, Pilger KCP, Marquesini TM, Martins EL. Promoção da saúde por meio da música em uma penitenciária feminina: relato de experiência. Rev Bras Promoç Saúde. 2021;34:11583. 